\title{
Preventive advice given by patients with type 2 diabetes to their offspring
}

\author{
Masakazu Nishigaki, Koji Kobayashi, Naoko Kato, Naoto Seki, Taeko Yokomura, \\ Mitsunao Yokoyama and Keiko Kazuma
}

\author{
ABSTRACT \\ Background \\ Patients' advice-giving behaviour could be a useful \\ preventive strategy for type 2 diabetes. \\ Aim \\ To investigate the conditions under which patients offer \\ advice to their offspring and to assess the factors that \\ facilitate advice giving.

\section{Design of study} \\ Cross-sectional observational study. \\ Setting \\ A general hospital with a diabetes clinic in a \\ metropolitan suburb in Japan.

\section{Method} \\ Parents with type 2 diabetes $(n=221)$ who had \\ offspring aged 20-49 years inclusive without diabetes \\ completed a self-administered questionnaire containing \\ items relating to advice-giving behaviour, demographic \\ characteristics, risk perception, and their disease status. \\ Results \\ A total of 184 (83.3\%) patients responded that parental \\ advice-giving behaviour is needed for their offspring, \\ while $138(62.4 \%)$ actually advised their offspring. \\ Multiple logistic regression analysis showed that \\ patients who were female (odds ratio $[O R]=1.94,95 \%$ \\ confidence interval $[\mathrm{Cl}]=1.03$ to $3.65, P=0.041$ ), \\ living with their offspring (OR $=1.92,95 \% \mathrm{Cl}=1.04$ to \\ $3.57, P=0.038)$, had complications $(\mathrm{OR}=2.74,95 \%$ \\ $\mathrm{Cl}=1.25$ to $6.00, P=0.029$ ), or perceived that their \\ offspring had a high risk of developing diabetes \\ (OR $=1.45,95 \% \mathrm{Cl}=1.09$ to $1.93, P=0.011$ ) were \\ most likely to advise their offspring.

\section{Conclusion} \\ Patients with type 2 diabetes recognised the need to \\ give advice about preventive behaviour to their \\ offspring but were not necessarily engaging in advice- \\ giving behaviour. Advice-giving behaviour was affected \\ by the parents' own disease status, their perception of \\ their offspring's risk of developing diabetes, and the \\ relationship between the patients and their offspring.

\section{Keywords} \\ diabetes mellitus, type 2; family; parent-child relations; \\ primary prevention.
}

\section{INTRODUCTION}

In recent years, the number of patients with type 2 diabetes has been increasing so rapidly that the active development and implementation of preventive strategies is urgently required. Effective prevention requires the identification of individuals who are at high risk of developing type 2 diabetes. Epidemiological studies have clearly shown that offspring of patients with type 2 diabetes are at increased risk of developing the disease,,$^{1,2}$ as they are likely to share the same genetic predisposition and have similar lifestyle habits to their parents. In addition, recent studies have suggested that the Japanese population is genetically predisposed to type 2 diabetes, ${ }^{3,4}$ so adoption of appropriate lifestyle habits seems likely to be particularly effective for the offspring of Japanese patients with diabetes.

Offspring of patients with type 2 diabetes are obviously at high epidemiological risk of developing diabetes, but previous studies have shown that such individuals tend to underestimate that risk. ${ }^{5,6}$ As having an appropriate understanding of risk and the seriousness of diabetes represent the first steps toward behavioural changes for

M Nishigaki, PhD, assistant professor; K Kobayashi, $P h D$, visiting researcher; $\mathrm{N}$ Kato, $\mathrm{MHlthSc}$, doctoral student; K Kazuma, PhD, professor, Department of Adult Nursing/Palliative Care Nursing, School of Health Sciences and Nursing, Graduate School of Medicine, University of Tokyo. N Seki, MD, clinical scientist; T Yokomura, RN, certified nurse; M Yokoyama, MD, clinical scientist, Social Insurance Funabashi Central Hospital, Chiba, Japan.

Address for correspondence

Masakazu Nishigaki, Adult Nursing, 7-3-1, Hongo, Bunkyo-ku, Tokyo, Japan. E-mail: nishigaki-tky@umin.ac.jp

Submitted: 28 February 2008; Editor's response: 3 June 2008; final acceptance: 1 September 2008.

(c)British Journal of General Practice

This article was originally online first. Cite this article as: Br J Gen Pract 2009; 59: 37-42. Advance online publication. DOI: 10.3399/bjgp09X394842 


\section{How this fits in}

The active development and implementation of preventive strategies is urgently required for relatives of patients who have type 2 diabetes because they are at higher risk of developing type 2 diabetes than people whose relatives do not have the disease. Patients' advice for their offspring aimed at preventing them from developing diabetes would be a practical and cost-effective preventive strategy, but little research into its effectiveness has been conducted. This survey aimed to fill that gap and suggests that patients' advice-giving behaviour would facilitate risk education of their offspring. prevention, ${ }^{7}$ the offspring of patients with diabetes may not find taking appropriate preventive actions easy. As such, some form of intervention may be warranted to facilitate the implementation of needed preventive behavioural changes. Previous research has shown that the most effective way to prevent diabetes in offspring of parents with diabetes is to intervene directly; ${ }^{8,9}$ this theory has also been based on established preventive strategies for populations at high risk of developing other conditions, such as obesity or prediabetes. ${ }^{10-13}$ However, direct intervention by medical professionals into the lives of healthy offspring is difficult, due to a lack of opportunities to make contact with them.

In some diseases for which a known genetic susceptibility exists, relatives who are affected can play effective roles in the adoption of preventive behaviour by those family members who are not affected..$^{14,15}$ This is particularly true for offspring of parents with diabetes, whereby parents are the most familiar individuals who have the disease and may be the people most capable of explaining the seriousness of diabetes and transmitting to their children useful information received from medical professionals. ${ }^{14,16}$

Given this perspective, patients have an important role in giving advice and warning their offspring to facilitate adoption of preventive behaviour. However, little research has described the role that parents can play, and little information is available regarding whether parents with diabetes actually do advise their offspring regarding the disease. ${ }^{17}$ The present study was conducted to investigate the precise conditions related to parents with type 2 diabetes giving advice to their offspring and to identify factors facilitating this behaviour.

\section{METHOD}

\section{Design}

Researchers conducted a cross-sectional observational study based on a self-administered questionnaire.

\section{Participants}

Patients with type 2 diabetes who were being treated at the diabetes clinic of a general hospital located in a city suburb of Japan were enrolled. Inclusion criteria were being aged $<75$ years and having offspring without diabetes who were $\geq 20$ years old but $<50$ years old. Patients were excluded if they had linguistic problems or any severe mental disorder.

\section{Procedures}

When patients visited the clinic, a clinician assessed whether they met the inclusion criteria. The diabetes status of their offspring was based on patient recognition. Those patients who were eligible to participate in the study received an explanation of the study by one of the investigators. After giving written informed consent to participate, each patient was asked to complete a questionnaire. Patients with more than one child were asked to specify one child when answering questions.

Most patients completed and returned the questionnaire straight away, but 11 took it home because they had no time to complete it immediately. These questionnaires were returned to the investigator's office by mail. The study was conducted from October to December 2005.

\section{Questionnaire}

The questionnaire, developed by the authors, is based on the hypothesis that the following patient status factors were related to advice giving, according to previous research that interviewed medical professionals about the prevention of diabetes in offspring: ${ }^{18}$

- physical/disease status;

- risk perception; and

- demographic characteristics.

All questions were closed: each question had two possible responses (yes or no). To assess patient attitudes to offering advice and whether advice was actually given, the questionnaire contained two outcome measure questions:

- 'Do you think that it is necessary to advise your child to take care of his/her lifestyle habits, such as diet or exercise, to prevent themselves from developing diabetes?'; and

- 'Have you actually advised your child to take care of his/her lifestyle habits, such as diet or exercise, to prevent themselves from developing diabetes?'.

Data about physical conditions and risk 
perception that could have an effect on preventive behaviours were also investigated. ${ }^{7,18,19}$ Physical status and conditions investigated were: body weight $(\mathrm{kg})$; height $(\mathrm{cm})$; family history; duration of diabetes (years); current treatment (insulin treatment, yes/no; oral medication, yes/no); whether the patient had been admitted to hospital for diabetes treatment/education; and whether the patient had experienced complications related to diabetes.

Risk perception-related factors that were investigated comprised knowledge of aetiological factors and perception of risk of developing diabetes in offspring. Responders were asked to rate the aetiological factors (lack of exercise, overeating, unbalanced diet, and genetics) on a fivepoint Likert scale from 1 (strongly agree) to 5 (strongly disagree), as well as their offspring's risk of developing diabetes by responding to the question: 'Compared with the general population, what is the likelihood of your child developing diabetes?'. Responses were chosen from: (1) very unlikely; (2) unlikely; (3) same as the general population in Japan; (4) likely; and (5) very likely.

Demographic characteristics comprised: sex; age; educational status; and living with/without offspring. The questionnaire contained approximately 50 questions about patients and 40 questions about their offspring. Participants completed the questionnaire in 20-30 minutes. Face validity of the questionnaire was confirmed in a pilot test.

\section{Statistical analysis}

Descriptive statistics for the basic characteristics and outcome measures were tabulated, then univariate logistic regression analysis was performed to assess which factors could facilitate the provision of advice. The dependent variable (main outcome measure) was the actual giving of advice (responses were converted: 'yes' to 1; 'no' to 0 ). Other items, such as basic characteristics, were treated as independent variables.

After univariate analysis, multivariate logistic analysis was performed to assess the relative influence of each factor after adjusting for other variables. To obtain a simpler model, variable selection was performed in two steps. Only variables that revealed a moderate relationship, which was indicated by a lower $P$-value $(P<0.2)$ on univariate analysis, were entered into the initial model, then automatic selection was conducted using the backward procedure.

SAS version 9.13 (SAS Institute, Cary, NC, US) was used for statistical analysis, and the level of significance was set at $P<0.05$.

\section{RESULTS}

Of the 233 patients who were eligible and visited the clinic during the study period, four patients declined to participate, three questionnaires were not returned, and five questionnaires were regarded as ineligible (two patients were aged $>75$ years, two described an adopted child, one lacked answers to more than $50 \%$ of all questions). Finally, results from 221 questionnaires (94.8\%) were analysed. Table 1 shows participant characteristics.

\section{Patient attitudes and provision of advice}

Table 2 shows results for patient recognition of the necessity to give advice, and patients who actually gave advice. A total of 184 (83.3\%) patients responded that they thought that giving advice to their offspring was necessary, but only 138 (62.4\%) patients actually advised their offspring.

\section{Factors facilitating the provision of advice}

Table 3 shows the results of univariate logistic regression analysis for which the dependent variable was the provision of advice ('Have actually advised offspring' = 1; 'Have not advised offspring' $=0$ ). About half of the independent variables were

\begin{tabular}{lc}
$\begin{array}{l}\text { Table 1. Characteristics of patients } \\
(\boldsymbol{n}=\mathbf{2 2 1}) .\end{array}$ \\
\begin{tabular}{lc} 
Characteristic & $n(\%)$ \\
\hline Sex & $95(43.0)$ \\
$\quad$ Females & $126(57.0)$ \\
\hline Males & $39(17.7)$ \\
\hline Educational status & $106(48.0)$ \\
Junior high school (13-15 years) & $71(32.1)$ \\
\hline High school (16-18 years) & $125(56.6)$ \\
\hline Tertiary education & $99(44.8)$ \\
\hline Living with their offspring & $49(22.2)$ \\
\hline Hospital admission related to diabetes & $59(26.7)$ \\
\hline Under insulin treatment & $130(58.8)$ \\
\hline Experiencing complications & Mean (SD) \\
\hline Family history of diabetes & $64.2(6.4)$ \\
\hline & $23.8(3.6)$ \\
\hline Age, years & $11.3(9.8)$ \\
\hline Body mass index, kg/m²
\end{tabular} \\
\hline Duration of diabetes, years & \\
\hline SD = standard deviation. &
\end{tabular}

Table 2. Patients' attitudes and actual provision of advice on diabetes prevention $(n=221)$.

\begin{tabular}{lll} 
Attitude & Yes, $n(\%)$ & No, $n(\%)$ \\
\hline It is necessary to advise offspring? & $184(83.3)$ & $37(16.7)$ \\
\hline Have you actually given advice? ${ }^{a}$ & $138(62.4)$ & $82(37.1)$ \\
\hline
\end{tabular}

${ }^{a}$ Missing $=1$. 
Table 3. Univariate logistic regression analysis of relationship between advice-giving behaviour a and parental factors $(n=220)$.

\begin{tabular}{lccc} 
& OR & $95 \% \mathrm{Cl}$ & $P$-value \\
\hline Sex (reference: male) & 2.09 & 1.18 to 3.71 & 0.012 \\
\hline Age & 1.02 & 0.98 to 1.06 & 0.420 \\
\hline Body mass index & 0.96 & 0.89 to 1.04 & 0.339 \\
\hline Educational status, years & 1.02 & 0.91 to 1.14 & 0.747 \\
\hline Living with offspring & 1.82 & 1.05 to 3.17 & 0.038 \\
\hline Having family history of diabetes & 1.58 & 0.91 to 2.76 & 0.105 \\
\hline Longer duration of illness & 1.03 & 1.00 to 1.07 & 0.032 \\
\hline Experience of hospital admission & 1.61 & 0.85 to 3.05 & 0.144 \\
\hline Having insulin treatment & 2.14 & 1.04 to 4.39 & 0.038 \\
\hline Receiving oral medication & 1.75 & 1.01 to 3.03 & 0.048 \\
\hline Experiencing complications & 3.01 & 1.49 to 6.11 & 0.002 \\
\hline Aetiological recognition & & & \\
Lack of exercise & 1.46 & 1.05 to 2.02 & 0.024 \\
Overeating & 1.28 & 0.89 to 1.85 & 0.186 \\
Unbalanced diet & 1.43 & 1.04 to 1.96 & 0.029 \\
Heredity & 1.26 & 0.98 to 1.63 & 0.075 \\
\hline Risk perception & 1.60 & 1.23 to 2.09 & $<0.001$ \\
\hline
\end{tabular}

${ }^{a}$ Missing $=1.0 R=$ odds ratio

Table 4. Multivariate logistic regression analysis of relationship between advice-giving behaviour and parental factors $(n=220)$.

\begin{tabular}{lccc} 
& OR & $95 \% \mathrm{Cl}$ & $P$-value \\
\hline Sex (reference: male) & 1.94 & 1.03 to 3.65 & 0.041 \\
\hline Living with offspring & 1.92 & 1.04 to 3.57 & 0.038 \\
\hline Experience of hospital admission & 1.61 & 0.85 to 3.05 & 0.144 \\
\hline Experiencing complications & 2.74 & 1.25 to 6.00 & 0.012 \\
\hline Risk perception & 1.45 & 1.09 to 1.93 & 0.011 \\
\hline Aetiological recognition, lack of exercise & 1.32 & 0.92 to 1.90 & 0.133 \\
\hline
\end{tabular}

$O R=$ odds ratio.
13 factors showing $P<0.2$ on univariate analysis, 'Having insulin treatment' was not entered into the initial model as this factor had a strong correlation with 'Experience of hospital admission' (Spearman's rank correlation coefficient $=0.48$ ). Variable selection using the backward elimination method resulted in a final model with six variables, of which four showed a significant OR (Table 4). The following factors were associated with giving advice to offspring: female sex (OR 1.94, $95 \% \mathrm{Cl}=1.03$ to $3.65, P=0.041$ ), both patient and offspring living together $(\mathrm{OR} 1.92,95 \% \mathrm{Cl}=1.04$ to $3.57, P=$ 0.038 ), the presence of complications (OR 2.74, $95 \% \mathrm{Cl}=1.25$ to $6.00, P=0.012)$, and the perception that offspring are at high risk of developing type 2 diabetes (OR 1.45, 95\% Cl $=1.09$ to $1.93, P=0.011$ ).

\section{DISCUSSION}

\section{Summary of main findings}

The present study investigated the advice given by patients with type 2 diabetes to their offspring, determined whether patients had provided advice to their offspring, and identified factors facilitating this behaviour. Most patients who participated (>80\%) recognised the need to advise their offspring, but were not necessarily engaged in advice-giving behaviours. Factors that facilitated or acted as barriers to giving advice can be summarised in three points: disease status, perception of risk, and the personal relationship between parent and child.

First, the disease status of the patient was found to be related to whether patients gave advice to their offspring. Factors that reflected disease severity, namely the use of insulin or oral treatment and the presence of medical complications, were clinically related to whether the patient had actually given advice to their offspring. Two possible explanations exist for this relationship. The more advanced the diabetes in the patient, the more the patient may think that they do not want their offspring to develop the same disease. Additionally, patients might not recognise the seriousness of their disease until they develop subjective symptoms. ${ }^{20}$ From the perspective of early prevention, patients should be aware that their offspring are at high risk of developing diabetes and take steps to help them prevent onset as soon as the patient is known to have diabetes.

Second, the patient's perception of the risk of diabetes in their offspring influenced whether they advised them. This means that the relationship between risk perception and direct preventive behaviour, as shown in many studies, can also be applied to advice giving. This can be regarded as indirect preventive behaviour. 
Third, the personal relationship between the parent and child was also related to actual advicegiving behaviour. Compared with male patients (fathers), female patients (mothers) gave advice more frequently. The rationale for this result is unclear, but it is possible that mothers pay more attention to lifestyle habits in their offspring than fathers. If this is the case, it might be important to intervene with male patients to help them pay attention to the prevention of diabetes in their offspring. The living arrangements of the parent and child was also a principal factor determining whether parents advise their offspring. Patients who live with their offspring can observe their lifestyle habits and easily give advice in a direct face-to-face manner. A separate living arrangement is, therefore, an obvious barrier to parents giving advice to their children. Under such conditions, patients require stronger motivation and support.

After adjusting for the effect of other factors on multivariate analysis, these three points were confirmed to correlate with actual parental advicegiving behaviours. This model provides meaningful information to plan educational interventions for patients aimed at facilitating advice-giving behaviours, to determine who should be preferentially targeted, and to ascertain the content that should be included in the intervention. Patients - particularly those who are male and living apart from their offspring - should be educated regarding proper recognition of the seriousness of disease and the risk to their offspring.

\section{Strength and limitations of the study}

This is the first study to investigate patients with type 2 diabetes with a focus on advice giving for offspring, which is thought to represent a practical, cost-effective strategy for prevention. ${ }^{21}$ The study achieved a high acceptance rate, even though participants were recruited from consecutive patients. This point strengthens the validity of the study.

There were some limitations, however, that need to be mentioned. All questions were answered based on the subjective perceptions of the patient. For example, interpretations of the term 'exercise' may differ among patients. More objective questions with clear definitions would be needed for further research. It was also noted that participants tend to report their own actions as being better than actual conditions. Taking this into account, patients were asked about advice giving from a perspective of both attitudes and actual actions. This method would also help patients to clarify their actual actions.
Some variables could potentially affect the provision of advice, such as psychological aspects of the parent-child relationship, along with physical, social, and psychological characteristics of the offspring of people with diabetes. Assessment of family relationships, particularly the parent-child relationship is also useful to enhance the effect of parental advice on preventive behaviour in offspring.

The design of this study displays some inherent limitations. Although the sample size was sufficient to establish a statistical model, the causal relationship between parental advice and related factors cannot be discussed based on this crosssectional study: a prospective study is required instead. In addition, the study's external validity is limited due to the sampling method. The study was conducted at a single institution in an urban area of Tokyo. As such, bias might exist in terms of higher educational status and greater knowledge of diabetes due to higher accessibility to various information sources. Patients were also asked to specify one child only, to avoid data clustering. Whether this method causes over- or underestimation of advice giving is unclear, as it is not known whether parents selected the child with the healthiest lifestyle in the family or the child at highest risk due to factors such as obesity and/or sedentary lifestyle.

Due to the lack of a control group of adults without diabetes, it is unclear whether these findings represent specific characteristics of Japanese patients with diabetes and their offspring.

\section{Comparison with existing literature}

The current authors previously reported the impressions of health professionals regarding the advice-giving behaviours of patients with diabetes. ${ }^{18}$ Health professionals thought that patients might not advise their offspring because they underestimate the risk of their developing diabetes or because they experience difficulty mentioning prevention to their offspring, perhaps due to their focus on managing their own diabetes. The results of the current study, which directly investigated patients, contradict the impressions of health professionals: patients are more attentive to the lifestyle habits of their offspring than suggested.

In Japan, since 2000, studies on genetic predispositions for various diseases, including diabetes, have been conducted as part of national projects $^{3,22}$ and the media have been actively reporting on lifestyle diseases. The present results may indicate that these national projects have raised the general awareness of diabetes. 


\section{Implications for future research and clinical practice}

From the perspective of clinical practice, providing accurate information not only regarding proper recognition of risk and disease seriousness, but also about effective prevention strategies, is essential for understanding the controllability of disease. ${ }^{23,24}$ Relatives of patients with type 2 diabetes tend to consume meals that are high in fat more frequently than the general population..$^{25}$ As such, a focus on the importance of lifestyle habits is crucial.

At this point in time, insufficient evidence exists regarding genetic predispositions to diabetes and lifestyle habits, such as diet intake, ${ }^{26}$ making it difficult for health professionals to explain these issues to patients and for patients to understand..$^{18}$ However, more data are gradually being gathered on interactions between genetic predisposition, lifestyle habits, and diabetes prevention. ${ }^{8,27-30}$ In the future, organising and presenting this information to patients and their relatives in an easy-to-understand manner will be important. This study revealed who should be preferentially targeted for intervention and demonstrated the importance of further research to investigate parent-child relationships for effective intervention.

\section{Funding body}

This study was supported by a Grant-in-Aid for Scientific Research (A) 16209064 from the Japan Society for the Promotion of Science to Keiko Kazuma

\section{Ethical approval}

The ethics committee of the University of Tokyo approved the study protocol (acceptance no 1236)

\section{Competing interests}

The authors have stated that there are none

\section{Acknowledgements}

We would thank to all the patients who agreed to participate in this study.

\section{Discuss this article}

Contribute and read comments about this article on the Discussion Forum: http://www.rcgp.org.uk/bjgp-discuss

\section{REFERENCES}

1. Valdez R, Yoon PW, Liu T, Khoury MJ. Family history and prevalence of diabetes in the US population: the 6-year results from the National Health and Nutrition Examination Survey (1999-2004). Diabetes Care 2007; 30(10): 2517-2522.

2. Kuzuya T, Matsuda A. Family histories of diabetes among Japanese patients with type 1 (insulin-dependent) and type 2 (non-insulindependent) diabetes. Diabetologia 1982; 22(5): 372-374.

3. Kadowaki T, Hara K, Yamauchi T, et al. Molecular mechanism of insulin resistance and obesity. Exp Biol Med (Maywood) 2003; 228(10): 1111-1117.

4. Matsuoka K. Genetic and environmental interaction in Japanese type 2 diabetics. Diabetes Res Clin Pract 2000; 50(Suppl 2): S17-22.

5. Kim J, Choi S, Kim CJ, et al. Perception of risk of developing diabetes in offspring of type 2 diabetic patients. Korean J Intern Med 2002; 17(1): 14-18.

6. Pierce M, Harding D, Ridout D, et al. Risk and prevention of type II diabetes: offspring's views. Br J Gen Pract 2001; 51(464): 194-199.

7. Rosenstock IM. Why people use health services. Milbank Mem
Fund Q 1966; 44(3) Suppl: 94-127.

8. Brekke HK, Jansson PA, Månsson JE, Lenner RA. Lifestyle changes can be achieved through counseling and follow-up in first-degree relatives of patients with type 2 diabetes. J Am Diet Assoc 2003; 103(7): 835-843

9. Brekke HK, Sunesson A, Axelsen M, Lenner RA. Attitudes and barriers to dietary advice aimed at reducing risk of type 2 diabetes in first-degree relatives of patients with type 2 diabetes. J Hum Nutr Diet 2004; 17(6): 513-521.

10. Tuomilehto J, Lindström J, Eriksson JG, et al. Prevention of type 2 diabetes mellitus by changes in lifestyle among subjects with impaired glucose tolerance. N Engl J Med 2001; 344(18): 1343-1350.

11. Diabetes Prevention Program (DPP) Research Group. The Diabetes Prevention Program (DPP): description of lifestyle intervention. Diabetes Care 2002; 25(12): 2165-2171.

12. Barclay C, Procter KL, Glendenning R, et al. Can type 2 diabetes be prevented in UK general practice? A lifestyle-change feasibility study (ISAIAH). Br J Gen Pract 2008; 58(553): 541-547.

13. Greaves CJ, Middlebrooke A, O'Loughlin L, et al. Motivational interviewing for modifying diabetes risk: a randomised controlled trial. Br J Gen Pract 2008; 58(553): 535-540.

14. Weil J. Psychosocial genetic counseling. New York: Oxford University Press, 2000.

15. Wilson BJ, Forrest K, van Teijlingen ER, et al. Family communication about genetic risk: the little that is known. Community Genet 2004; 7(1): 15-24.

16. Becker MH, Maiman LA. Sociobehavioral determinants of compliance with health and medical care recommendations. Med care 1975 ; 13(1): 10-24.

17. Gnanalingham MG, Manns JJ. Patient awareness of genetic and environmental risk factors in non-insulin-dependent diabetes mellitus-relevance to first-degree relatives. Diabet Med 1997; 14(8): 660-662.

18. Nishigaki M, Kobayashi K, Shibayama T, et al. Attitude of diabetes care specialists to prevention of diabetes to relatives of patients with type 2 diabetes. [Japanese]. J Japan Diab Soc 2006; 49(8): 669-676.

19. Eiser JR, Eiser C, Riazi A, et al. Screening for diabetic retinopathy is well received by patients and may improve self-management intentions. Diabet Med 2001; 18(10): 835-841.

20. Murphy E, Kinmonth AL. No symptoms, no problem? Patients' understandings of non-insulin dependent diabetes. Fam Pract 1995; 12(2): 184-192.

21. Bonomo K, Fiora E, Caccavale A, et al. Diabetes prevention strategy in offspring of type 2 diabetic patients with a direct involvement of the diseased parents. Nutr Metab Cardiovasc Dis 2005; 15(3): 237-238.

22. Haga H, Yamada R, Ohnishi Y, et al. Gene-based SNP discovery as part of the Japanese Millennium Genome Project: identification of 190,562 genetic variations in the human genome. Singlenucleotide polymorphism. J Hum Genet 2002; 47(11): 605-610.

23. Marteau TM, Lerman C. Genetic risk and behavioural change. BMJ 2001; 322(7293): 1056-1059.

24. Pierce M, Hayworth J, Warburton F, et al. Diabetes mellitus in the family: perceptions of offspring's risk. Diabet Med 1999; 16(5): 431-436.

25. Adamson AJ, Foster E, Butler TJ, et al. Non-diabetic relatives of Type 2 diabetic families: dietary intake contributes to the increased risk of diabetes. Diabet Med 2001; 18(12): 984-990.

26. O'Rahilly S, Barroso I, Wareham NJ. Genetic factors in type 2 diabetes: the end of the beginning? Science 2005; 307(5708): 370-373.

27. Uusitupa M. Gene-diet interaction in relation to the prevention of obesity and type 2 diabetes: evidence from the Finnish Diabetes Prevention Study. Nutr Metab Cardiovasc Dis 2005; 15(3): 225-233.

28. Franks PW, Mesa JL, Harding AH, Wareham NJ. Gene-lifestyle interaction on risk of type 2 diabetes. Nutr Metab Cardiovasc Dis 2007; 17(2): 104-124.

29. Hu G, Rico-Sanz J, Lakka TA, Tuomilehto J. Exercise, genetics and prevention of type 2 diabetes. Essays Biochem 2006; 42: 177-192.

30. Nakanishi S, Yamane K, Kamei N, et al. Relationship between development of diabetes and family history by gender in JapaneseAmericans. Diabetes Res Clin Pract 2003; 61(2): 109-115. 